\title{
O TEATRAL DO MUNDO
}

\author{
Luiz Claudio Vieira de Oliveira \\ UFMG
}

\begin{abstract}
RESUMO
Este ensaio busca trabalhar o elemento teatral na obra de Guimarães Rosa, entendendo-o como processo de representação do real por meio de sua transformação em texto/discurso, e como processo de carnavalização pela abolição da hierarquia e multiplicação das versões.
\end{abstract}

\section{PALAVRAS - CHAVE}

representação, texto/discurso, mimese

"teatral do mundo" é uma expressão que aparece em Grande sertão: veredas, de Guimarāes Rosa, exemplificando uma constante em sua obra: a referência ao teatro como o local onde se dá, por excelência, a representação. O sintagma "teatral do mundo" não está considerando, apenas, o teatro ou a representação teatral em seu sentido mais simples, mas tomando a ambos como uma metáfora da mimese. Trata-se da relação entre o real e sua transformação em objeto artístico, ou seja, texto e discurso. Como texto, o real adquire uma forma que the é própria e pela qual pode ser visto, de modo mais ou menos evidente, atrelado, ao mesmo tempo, a uma hiper e a uma transtextualidade. ${ }^{1}$ É o resultado do entrelaçar dos fios, o tecido com sua trama, sua forma e seus efeitos. Isso facilita a recepção do objeto artístico pelo leitor. Como discurso, o real se torna passível de múltiplas intervençōes, de inúmeros enunciadores, transformando-se a cada enunciação e só se mantendo graças a elas. Texto e discurso são duas faces complementares dessa apreensão do real, que paradoxalmente o mantêm e o modificam. Pode-se inferir que o real terá existência enquanto efeito textual e discursivo, só se constituindo ao ser representado ou traduzido mimeticamente em objeto artístico.

O teatro, em Guimarães Rosa, como metáfora da relação mimética estabelecida entre o texto/discurso e o real, difere do conceito de mimese apresentado em vários dos livros d'A República, ${ }^{2}$ de Platão, e em especial no Mito da Caverna, citado em "Aletria e hermenêutica", de Tutaméia. Enquanto o Mito considera as sombras projetadas como ilusão, em tudo diversas de um real que as teria originado, Guimarães Rosa as toma como realidade. A diferença entre as concepções é fundamental. Platão, tal como se vê nos vários livros d'A República, desconfiava da literatura, concebida como instância produtora de sombras, de fantasmas, ou seja, de ilusões, capazes de obscurecer o conhecimento do real e da verdade.

${ }^{1}$ Genette. Palimpsestes, p.7-14.

${ }^{2}$ Platon. La Republique. Livros III, VII e X. 
Para Guimarāes Rosa, o acesso ao real ou à verdade só é possível se se aceita a multiplicidade de representações desse real: o que existem são versões que têm o mesmo valor, podendo-se escolher uma ou outra, sendo desnecessária a eleição de uma, privilegiada. Nesse sentido, ocorre um processo de carnavalizaçāo em sua obra, ou seja, em lugar de uma "verdade" ou de um "real" preexistentes e originais, existe é o mundo à revelia, a inversão dos valores, a mudança constante. Conforme Bakhtin expõe na introdução de A cultura popular na Idade Média e no Renascimento, ${ }^{3}$ o carnaval se caracteriza, entre outras coisas, pela ruptura da hierarquia.

Na obra de Guimarães Rosa, o teatral do mundo, além de expresso pela permanente encenação da linguagem que nela se realiza, consiste também de referências explícitas ao teatro, ao jogo de cena, à equivalência entre teatro e mundo. Já em Sagarana encontrase uma menção ao teatro. Em "A volta do marido pródigo", Lalino Salãthiel é o criador de ilusões, é o contador e o inventor de estórias, nas quais passa a acreditar e em que atua como personagem. "Quem sabe, a gente podia representar esse drama, hem seu Laio?... como é que chama mesmo?... 'O Visconde Sedutor'... Foi o que você disse, não foi?" " Da mesma forma que inventa as peripécias do drama e, por meio das palavras, constrói situaçōes em que os outros personagens vão se enredar, Lalino Salãthiel também inventa a própria vida: o real é o que se diz ser o real. E isso lhe possibilita passar de uma instância a outra.

Em "Pirlimpsiquice", de Primeiras estórias, o tema da representação teatral é evidente. Aqui se destaca o predomínio das versōes. Há um jogo entre as múltiplas variantes: a versão oficial - "A história do Dr. Famoso" - , a dos atores, a dos opositores, e a do Zé Boné. Falhando a versão oficial por um pequeno detalhe, entram em cena os episódios alternativos, desencadeados pela atuação do Zé Boné. A falha é sintoma de que o real, aqui tomado metonimicamente pela postura pedagógico-autoritária dos padres, que se queria organizado e rígido, não se mantém e é capaz de ruir. A verdade - um conjunto de virtudes religiosas e civis, consubstanciadas na peça oficial - não se sustenta ante a força das representações, capaz de subtrair os atores ao real em que ela vigoraria.

Tem lugar aqui o conceito de "a outra cena", de O. Mannoni. ${ }^{5}$ É um conceito eficiente, que explica a peculiaridade que têm o terreno do jogo, o palco teatral ou a página de ficção de funcionarem como um espaço privilegiado para onde se pode ir, distinto do espaço real, e do qual se pode voltar. Esse locus apresenta-se numa suspensão do espaço e do tempo reais, onde tudo é possível, onde se realizam todas as fantasias, mas, como lembra Mannoni, também onde se pode "ser sem ser". Esta efemeridade é fundamental para o conceito de "outra cena" e para a concepçāo da arte como possibilitadora de uma distância em relação ao real e de uma visão (ou visōes) diferente(s) sobre o real. Representa a abertura que o imaginário favorece, em oposição à rigidez do simbólico. É o espaço aonde se pode ir, mas onde não se pode permanecer. Por isso, o narrador de "Pirlimpsiquice" se esforça para sair "do fio, do rio, da roda, do representar sem fim" e voltar à realidade da qual partira. Permanecer na "outra cena" significaria a

\footnotetext{
${ }^{3}$ Bakhtin. A cultura popular na ldade Média e no Renascimento, p.8.

${ }^{4}$ RosA. Sagarana, p. 91 .

${ }^{5}$ Mannoni. Chaves para o imaginário, p.98-9.

${ }^{6}$ Rosa. Primeiras estórias, p.47.
} 
loucura, em que há a indeterminação de tempo e de espaço. Esse real para o qual se volta, o simbólico, é aquele em que predomina a versão única, original, da Lei, e, portanto, tida como verdadeira e em que se recusam todas as outras versōes como falsas e mentirosas.

O conto "A benfazeja", de Primeiras estórias, chama a atenção pela sua teatralização, uma vez que se encena aos olhos do leitor/espectador. O conto não tem um narrador que se dirija, de alguma forma, ao leitor. Trata-se de um diálogo mantido entre um personagem e os moradores de um vilarejo, acerca da Mula Marmela, de seu enteado, o cego Retrupé, e seu finado marido, o Mumbungo. Nesse diálogo, como em outros textos rosianos, não há registro da fala do interlocutor. Um personagem fala durante todo o tempo, num procedimento que lembra um diálogo. É evidente que não fala sozinho, para si mesmo. Não é um fluxo de consciência, um "monólogo interior", cerebrino. O texto evidencia que esta longa fala se dirige a um interlocutor que não aparece, mas que tem suas reações e suas falas refletidas e registradas na voz do narrador protagonista. Este monólogodiálogo é uma característica da obra de Guimarães Rosa. Grande sertão: veredas, "Meu tio, o Iauaretê", "A benfazeja", "O espelho" e outros textos a utilizam com grande eficácia. O recurso consiste na apropriação de uma característica própria da oralidade - o ato de contar estórias - e da técnica teatral - a exclusão do narrador. As narrativas se iniciam sem que haja uma introdução formal, que situe temporal e espacialmente a cena. Isto se deduz no decorrer da narrativa, cujas informações permitem ao leitor/espectador compor o cenário e visualizar os personagens. Em alguns dos textos citados, a narrativa faz uso de um travessão que indica claramente a mudança de registro: de oral para escrito. O emprego desse recurso gráfico, ainda que uma única vez, indica a sucessão de interlocutores: houve uma intervenção anterior, uma pergunta ou uma observaçāo que motiva a longa resposta do narrador.

Grande sertão: veredas inicia-se pelo travessāo, antecedendo a fala "Nonada. Tiros que o senhor ouviu foram de briga de homem não. Deus esteja." Vê-se que é uma resposta a uma pergunta anterior, não registrada, sobre os tiros que supostamente se fizeram ouvir. Essa pergunta anterior fica sem registro e o leitor é introduzido, teatralmente, in media res. Em "O espelho", há o mesmo processo. A presença de um interlocutor é clara: "Se quer seguir-me, narro-lhe... (...) O senhor, por exemplo, que sabe e estuda (...)"8 Em "A Benfazeja", não há o recurso ao travessão, mas os efeitos obtidos são os mesmos: "Sei que não atentaram na mulher; nem fôsse possível. (...) Acham ainda que não valia a pena? (...) Vocês todos nunca suspeitaram que ela pudesse arcar-se no mais fechado extremo, nos domínios do demasiado?" Percebe-se que um personagem interpela vários outros, moradores de um lugarejo perdido no interior das Minas Gerais, reprovando-os pela hipocrisia e pela maldade mansa. Como o texto não é explicitamente teatral e como não há a didascália que oriente o leitor/espectador, esse personagem acaba por exercer, indiretamente, a função de narrador. Para que as informaçóes cheguem ao leitor, é preciso que, em sua fala, sejam enxertados episódios anteriores ao momento em que interpela seus ouvintes.

\footnotetext{
${ }^{7}$ Rosa. Grande sertão: veredas, p.3.

${ }^{8}$ Rosa. Primeiras estórias, p.71.

${ }^{9}$ IBIDEM. p. 125.
} 
Em "Meu tio, o lauaretê", um personagem, o Macuncôzo, também responde às perguntas de um outro, ao mesmo tempo em que o interroga e vai contando sua estória: “-Hum? Eh-eh... É. Nhor sim. Ã-hã, quer entrar, pode entrar... Hum, hum. Mecê sabia que eu moro aqui? Como é que sabia? Hum-hum... Eh." ${ }^{10}$ Aqui também, para que o leitor/espectador se inteire de toda a estória, há dois planos narrativos: o do presente, que é o da cena em desenvolvimento, e o do passado, que explica e justifica o presente. Ambos são tecidos pela fala do narrador. Guardadas as devidas proporçōes, trata-se do mesmo processo utilizado em Grande sertão: veredas. A diferença está no seguinte: à medida que narra, o Macuncôzo se revela cada vez mais: acaba por transformar-se em onça e atacar seu ouvinte. O narrador que conta sua história a um suposto caçador identifica-se progressivamente com o mestiço assassino, que não distingue mais os limites entre homem e animal; Riobaldo, ao narrar, pretende desvincular sua imagem de narrador de sua imagem de jagunço. "O jagunço Riobaldo. Fui eu? Fui e nāo fui. Não fui! porque não sou, não quero ser. Deus esteja!" 1

O conto "Cara-de-Bronze", de Corpo de baile, indica a radicalização do processo em Guimarães Rosa. Inclui outros recursos que o aproximam do teatro, do cinema, do texto técnico. Depois de o conto se iniciar por uma forma narrativa tradicional, passa a registrar o diálogo que se estabelece entre os vaqueiros e Moimeichego, cuja seqüência lembra a sucessão de falas de um texto teatral, inclusive com a didascália. Por exemplo: "Entram os vaqueiros TADEU e SĀOS, seguidos dos vaqueiros ZAZO, JOSÉ UÉUA, RAYMUNDO PIO e FIDÉLIS."12 De repente, da página 92 à página 96 há um roteiro de cinema, com seus planos gerais, planos americanos e sua didascália. Depois, mais à frente, há citações de Dante, Platão e do Cântico dos Cânticos e notas de pé de página em que um dos anagramas de Guimarães Rosa é referido. ${ }^{13}$ Páginas adiante, há uma citação de Goethe, em alemão, e de fragmentos do Chandogya-Upanixad. Essa mistura de convenções faz com que os limites hipertextuais e transtextuais sejam rompidos. O leitor/ espectador tem dificuldades para reconhecer o texto que está lendo e para distinguir a instância discursiva que profere. Afinal, que sujeito é responsável pela enunciação? Guimarães Rosa, Moimeichego, o anagramático Oslino Mar, ou o narrador que inicia o conto dizendo "No Urubùquaquá. Os campos do Urubùquaquá - urucuias montes, fundōes e brejos. No Urubùquaquá, fazenda-de-gado: a maior - no meio - um estado de terra."? ${ }^{14}$ Executada como uma estratégia do autor-modelo, tal como é concebido por Umberto Eco, a multiplicidade de narradores dificulta que se distingam o Sujeito Comunicante e o Sujeito Enunciador, ao mesmo tempo em que provoca a fusão dos níveis intra e extratextais.

Todo texto/discurso se constrói como um pacto entre o leitor/ouvinte e o narrador. São duas instâncias diferentes que se interpenetram. O narrador pertence ao universo ficcional, enquanto o leitor/ouvinte está no mundo real. Cria-se um movimento duplo: vai-se ao texto/discurso da mesma forma que ele vem ao mundo real. Como esse mundo

\footnotetext{
${ }^{10}$ Rosa. Estas estórias, p.126.

1 Rosa. Grande sertão: veredas, p.166.

${ }_{12}$ Rosa. No Urubùquaquá, no Pinhém, p.78.

${ }^{13}$ IBIDEM. p. 117.

1. IBIDEM. p.73.
} 
real é construído por signos e, em última instância, é também um texto/discurso, podese dizer que o trânsito se faz entre textos/discursos e não mais entre esses e o mundo real. O "teatral do mundo" consiste nessa ambigüidade, nessa ruptura de fronteiras, nessa impossibilidade de "demarcar os pastos", de "manter o bom longe do ruim", como queria o personagem Riobaldo. Tanto os prefácios das Terceiras estórias quanto a ficção rosiana como um todo acabam por romper as barreiras entre o real e a ficção, entre o grotesco e o excelso, entre o chiste e a filosofia, entre o rasteiro e o transcendental. Destaca-se que não há diferença entre narradores e ouvintes, entre personagens e pessoas, sendo possível mudar de posição livremente. Riobaldo afirma: "Vida devia de ser como na sala do teatro, cada um inteiro fazendo com forte gosto seu papel, desempenho." 15 Assim, não haveria separação entre vida e a "sala do teatro", como não haveria separação entre real (verdade) e ficção (mentira). O conceito tradicional de mimese, em que se valoriza a fidelidade com o modelo e, mais que isso, a integridade do modelo em relação à cópia, deixa de prevalecer em benefício da acepção de mimese como transgressão e como cópia infiel. Em Guimarães Rosa, o "teatral do mundo" se faz como movimento, multiplicação de versōes, abolição de fronteiras, interpenetração de instâncias, travessias.

\title{
A
}

\begin{abstract}
This essay trys to show how the theatrical element in Guimarães Rosa represents the real by transforming it into a text/discourse and carnavilizing it through the demolition of hierarchy and the multiplication of versions.
\end{abstract}

\section{KEY WORDS}

representation, text/discourse, mimesis

\section{REFERÊNCIAS BIBLIOGRÁFICAS}

Bakhtin, Mikhail. A cultura popular na Idade Média e no Renascimento - o contexto de François Rabelais. Trad. Yara Frateschi Vieira. São Paulo: Hucitec, Brasília: Editora Universidade de Brasília, 1987.

Eco, Umberto. Seis passeios pelos bosques da ficção. Trad. Hildegard Feist. São Paulo: Companhia das Letras, 1994.

Genette, Gérard. Palimpsestes: la littérature au second degré. Paris: Seuil, 1982.

Mannoni, O. Chaves para o imaginário. Trad. Ligia Maria Pondé Vassalo. Petrópolis: Vozes, 1973. Platon. La Republique; Oeuvres completes. Paris: Garnier, 1950. v. 4.

ROSA, João Guimarães. Estas estórias. 2.ed. Rio de Janeiro: José Olympio, 1976.

RosA, João Guimarães. Grande sertão: veredas. Rio de Janeiro: José Olympio, 1970.

RosA, João Guimarães. No Urubùquaquá, no Pinhém. 4.ed. Rio de Janeiro: José Olympio, 1969.

RosA, João Guimarães. Primeiras estórias. 3.ed. Rio de Janeiro: José Olympio, 1967.

RosA, João Guimarães. Sagarana. 40.ed. Rio de Janeiro: Nova Fronteira, 1984.

Rosa, João Guimarāes. Tutaméia: terceiras estórias. 3.ed. Rio de Janeiro: José Olympio, 1969.

${ }^{7}$ RosA. Grande sertão: veredas, p. 187. 